\title{
On Econometric Analysis of the Relationship between GDP and Tourism Income in Guizhou, China
}

\author{
Wei Wang ${ }^{1} \&$ Haiying $\mathrm{Ma}^{1}$ \\ ${ }^{1}$ School of Economics, Northwest University for Nationalities, Lanzhou, China \\ Correspondence: Haiying Ma, Associate professor, School of Economics, Northwest University for Nationalities, \\ Lanzhou 730124, China. E-mail: lxmahaiying8888@163.com
}

Received: June 9, 2015

Accepted: June 29, 2015

Online Published: July 12, 2015

doi:10.5430/ijba.v6n4p41

URL: http://dx.doi.org/10.5430/ijba.v6n4p41

\begin{abstract}
With the rapid development of reform and opening up, and the swift progress of the Western Development, Guizhou tourist income has hit record highs year by year, which promoted rapid expansion of the tertiary industry and thereby made GDP in Guizhou reach a new level, when people's living standards were also improved significantly. The paper studies the relationship between GDP in Guizhou and tourist income based on the economic analysis of the relevant data in the last two decades, and predicts the future development of Guizhou tourism industry.
\end{abstract}

Keywords: econometric analysis, GDP, tourist income, Guizhou Province

\section{Introduction}

Throughout the world economy, tertiary industry as an emerging industry has gradually become an important pillar in each country. The rapid development of social division of labor and industry in developed countries is the prerequisite for the advance of tertiary industry. The construction and development of the free market system is the lifeline for the progress of tertiary industry. The development level of various service industries provides vast space for the expansion of tertiary industry. The progress of urbanization is the booster for the tertiary industry. Therefore, it is necessary to create a favorable environment for the development of tertiary industry through multiple approaches. With the deepening reform and opening up and advancing market economy, tertiary industry has achieved a swift progress, and today tertiary industry has become the most important economic pillar in many developed countries, and the rise of tourism industry has brought more opportunities for its development, so that in some countries, tertiary industry has become their most important industry and primary source of GDP. As a modern industry, tourism has drawn more and more attention, and has broken through geographic restrictions due to the increase in personal income and the development in transportation - international travel is no longer a dream. Under the premise of fulfilled material life, there is a growing pursuit for spiritual enjoyment. In this context, the world has set off a wave of travelling, which led to the speedy growth of tourism and progress of tertiary industry.

Throughout the development process, China's tertiary industry grew slowly for a long term with a low proportion in the national economy before the reform and opening up, which was mainly influenced by three factors. The first is deviation in economic theory: the service sector was deemed as a non-productive sector that created no social wealth, when the increase in its proportion was regarded as the concentrated expression of the decadent and parasitic nature of imperialism. The second is deviation in development strategies: tertiary industry wasn't timely included in the national economic development strategies when industry and agriculture had been greatly developed. The third is policy failure: the long-standing low-price service system harmed the interests of the service industry, when criticism of service activities as capitalism dampened the enthusiasm for the development of service industry. After the reform and opening up, there were two development periods of China's tertiary industry. The first period was from 1978 to 1991, the recovery period of rapid growth, characterized with high growth of tertiary industry, rapid increase in its proportion, and non-significant improvement in structure, when tertiary industry growth was mainly driven by traditional services. The second period spanned from 1992 to 2006, the period of structural improvement, featured with slowed growth of tertiary industry, relative stability in its proportion, significant improvement in structure, when emerging industries and high value-added industries had a good growth momentum.

Since 1978, China's tourism industry has entered a new historical period thanks to the development of reform and opening. After 30 years of development, China has become the world tourist destination and established its 
distinctive image in the international arena, which has enhanced the mutual exchanges between China and the other countries, and expanded China's international influence. China has formed a tourism development pattern that attaches importance to tourism development from top to bottom, and encourages participation of different parties. Tourism plays an active and important role in national economic, cultural, and social construction and international exchanges, and becomes an important part in improving the national living standard and building a moderately prosperous society. After 30 years of reform and opening up, China's tourism industry, from small to large, from weak to strong, has become an important vigorous force in promoting China's economic and social progress and boosting the global tourism development. Clearly, tourism is a comprehensive economic industry. Recognition of this nature, as an important breakthrough for tourism development ideas, will help to reach a consensus in the whole society to construct, expand and promote China's tourism industry. The clear recognition of the industrial nature has enhanced the awareness of tourism development, gathered capital for the tourism industry, optimized the environment for tourism development, and laid a solid foundation for fostering the tourist economy, constructing the tourism system, and realizing the tourism functions.

Guizhou is rich in tourism resources, and thus tourism should be the pillar industry for Guizhou. As China joined WTO, China has become increasingly open to the outside world, plus the implementation of the Western Development strategy - these trends will bring good opportunities for tourism development in Guizhou. Since the reform and opening up, Guizhou tourism has maintained a good momentum of development in the context of the rapid development of China's tourism industry, with growing tourist income year by year. In 2009, the domestic tourist income of Guizhou reached 79.769 billion yuan. The rapid development of Guizhou tourism was attributed to many factors, among which the domestic demand from the residents in Guizhou played an important role in the tourism development, and residents' income had a major impact on the tourist income. However, the income from Guizhou tourism and the related industries accounted for a very low percentage in GDP. Specifically, in 2007, 2008, and 2009, the total income of Guizhou tourism accounted for respectively $18.97 \%, 19.46 \%$, and $21.55 \%$ of the provincial GDP. This indicates that there is a huge room for tourism development in Guizhou. Therefore, the study on the influence of Guizhou residents' income on its tourism development has important practical significance to maintaining a sustainable and rapid growth of Guizhou tourism, expanding the tourism market demand within the province, and stimulating the provincial economic growth.

From 1990 to 2009, GDP in Guizhou has increased to 391.268 billion in 2009 from 26.014 billion in 1990, with a 15-time growth, while tourism has increased to 79.769 billion yuan in 2009 from 0.09 billion yuan in 1990, with a 886-time increase. It can be seen that GDP in Guizhou growth was far slower than its tourism growth, indicating the considerable development prospects of Guizhou tourism. Guizhou has advantaged tourism resources, thus in the future, the development of tertiary industry especially tourism will be the highlight of GDP in Guizhou growth. We will apply the knowledge we have learned to explore the relationship between GDP in Guizhou and its tourist income, and conduct relevant econometric analysis.

\section{Model Setting and Data Collection}

GDP growth is closely related with tourist income, as tourist income growth will certainly facilitate GDP growth, while GDP growth will in return promote tourism development, and finally the increase of tourist income. Because tourism is a hot industry in contemporary world, a number of scholars have conducted some researches about it. Analysis and study of tourism, a branch of the tertiary industry, are beneficial to the overall grasp of the tertiary industry. With the economic development, the tertiary industry will occupy a much higher percentage in GDP, while the primary industry, i.e. agriculture, will take up a smaller percentage. The secondary industry stays almost the same as before. However, with the market economy development, the tertiary industry will increase its share year by year, it is reasonable to expect that the percentage of the secondary industry in GDP will decrease correspondingly. Based on the data collected in surveys, a simple linear regression model is set up for Guizhou GDP and tourist income, so as to analyze their relationship. The following model is set up and its formula is:

$$
Y_{t}=\beta_{0}+\beta_{1} X_{t}+U_{t}(t=1,2, \cdots n)
$$

In the formula, $y$ means Guizhou GDP; $x$ means the variation of Guizhou tourist income; $\beta 0$ and $\beta 1$ are parameters to be estimated; $\mu \mathrm{i}$ is random error, which represents other factors that influence GDP.

The data used in this paper with regard to GDP and domestic tourist income are collected from China Statistical Yearbook and Guizhou Province Statistical Yearbook 1990-2009 as shown in Table 1 and Table 2. 
Table 1. The domestic tourist income and resident income in Guizhou Province 100 million Yuan, Yuan

\begin{tabular}{cccccccc}
\hline Year & $\begin{array}{c}\text { urban } \\
\text { domestic GDP } \\
\text { income }\end{array}$ & $\begin{array}{c}\text { resident } \\
\text { per capita } \\
\text { disposable } \\
\text { income }\end{array}$ & $\begin{array}{c}\text { rural } \\
\text { resident per } \\
\text { capita net } \\
\text { income }\end{array}$ & Year & $\begin{array}{c}\text { Domestic } \\
\text { GDP income }\end{array}$ & $\begin{array}{c}\text { urban resident } \\
\text { per capita } \\
\text { disposable } \\
\text { income }\end{array}$ & $\begin{array}{c}\text { resident per } \\
\text { capita net } \\
\text { income }\end{array}$ \\
\hline 1990 & 0.19 & 1399.36 & 435.14 & 2000 & 57.95 & 5121.22 & 1374.16 \\
1991 & 0.66 & 1593.54 & 465.53 & 2001 & 75.81 & 5451.91 & 1411.73 \\
1992 & 2.21 & 1887.51 & 506.13 & 2002 & 99.86 & 5944.02 & 1489.91 \\
1993 & 4.29 & 2300.38 & 579.67 & 2003 & 114.36 & 6569.2 & 1564.66 \\
1994 & 4.28 & 3196.06 & 786.84 & 2004 & 161.02 & 7322.04 & 1721.55 \\
1995 & 7.18 & 3916.25 & 1086.62 & 2005 & 242.83 & 8147.13 & 1877 \\
1996 & 8.53 & 4210.74 & 1276.67 & 2006 & 377.79 & 9116.61 & 1984.62 \\
1997 & 30.81 & 4438.05 & 1298.54 & 2007 & 504.04 & 10678.4 & 2373.99 \\
1998 & 35.14 & 4566.17 & 1334.46 & 2008 & 643.62 & 11758.76 & 2796.93 \\
1999 & 43.75 & 4935.47 & 1363.07 & 2009 & 797.69 & 12862.53 & 3005.41 \\
\hline
\end{tabular}

Source: organized according to China Statistical Yearbook and Guizhou Province Statistical Yearbook 1990-2009

Table 2. Guizhou GDP and tourist income 1990-2009

\begin{tabular}{|c|c|c|}
\hline Year & GDP & Tourist income \\
\hline 1990 & 260.14 & 0.19 \\
\hline 1991 & 296.36 & 0.66 \\
\hline 1992 & 339.91 & 2.21 \\
\hline 1993 & 417.69 & 4.29 \\
\hline 1994 & 524.46 & 4.28 \\
\hline 1995 & 636.21 & 7.18 \\
\hline 1996 & 723.18 & 8.53 \\
\hline 1997 & 805.79 & 30.81 \\
\hline 1998 & 858.39 & 35.14 \\
\hline 1999 & 937.5 & 43.75 \\
\hline 2000 & $1,029.92$ & 57.95 \\
\hline 2001 & $1,133.27$ & 75.81 \\
\hline 2002 & $1,243.43$ & 99.85 \\
\hline 2003 & $1,426.34$ & 114.36 \\
\hline 2004 & $1,677.80$ & 161.02 \\
\hline 2005 & $2,005.42$ & 242.83 \\
\hline 2006 & $2,338.98$ & 377.79 \\
\hline 2007 & $2,884.11$ & 504.04 \\
\hline 2008 & $3,561.56$ & 643.82 \\
\hline 2009 & $3,912.68$ & 797.69 \\
\hline
\end{tabular}

Source: China Statistical Yearbook 1990-2009 


\section{Empirical Analysis}

\subsection{Regression Analysis}

Software EVIEWS is adopted to conduct regression analysis for the data in the above tables.

\subsubsection{Analysis of Correlation Coefficient between Variables}

The experiment results show that Guizhou province national income $\mathrm{Y}$ and tourist income $\mathrm{X}$ indicate high-positive correlation, the correlation coefficient is about 0.958737 . This shows that it is suitable to use the simple linear regression model to explain their relationship.

\subsubsection{Drawing of Scatter Diagram}

According to the methods in the operating principles, the scatter diagram of the explained variable $\mathrm{Y}$ and the explaining variable $\mathrm{X}$ is drew as follows in Figure 1 .

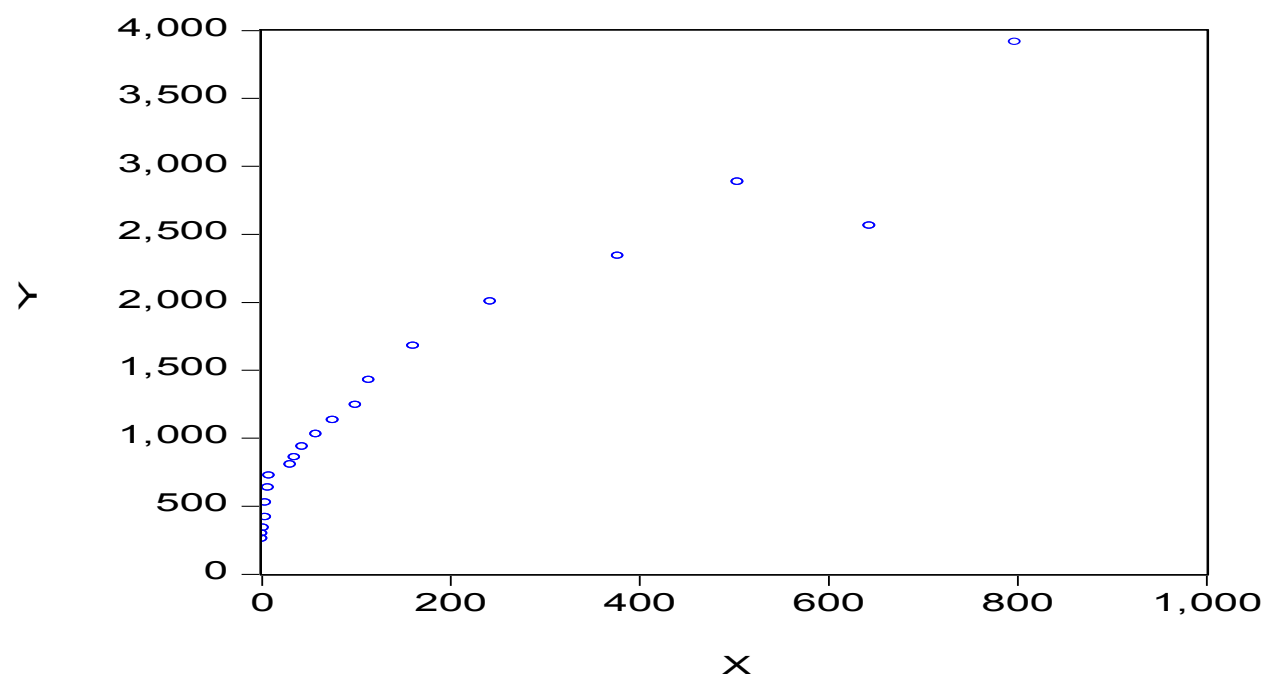

Figure 1. scatter diagram of variables

According to the diagram, most of the scatter points distribute along a straight line. Thus, national income Y and tourist income $\mathrm{X}$ also present high-positive relationship.

\subsubsection{Seting up Regression Equation}

Conduct regression for the statistics and obtain the results as below:

Dependent Variable: $\mathrm{Y}$

Method: Least Squares

Date: 10/20/13 Time: 14:54

Sample: 19902009

Included observations: 20

\begin{tabular}{ccccr}
\hline \hline Variable & Coefficient & Std. Error & t-Statistic & Prob. \\
\hline \hline $\mathrm{X}$ & 0.065308 & 0.213451 & 20.97610 & 0.0000
\end{tabular}




\begin{tabular}{cccc} 
C & 631.5453 & 59.78367 & 10.56384 \\
\hline \hline R-squared & 0.960698 & Mean dependent var & 1350.657 \\
Adjusted R-squared & 0.958515 & S.D. dependent var & 1075.392 \\
S.E. of regression & 219.0344 & Akaike info criterion & 13.71097 \\
Sum squared resid & 863569.0 & Schwarz criterion & 13.81055 \\
Log likelihood & -135.1097 & Hannan-Quinn criter. & 13.73041 \\
F-statistic & 439.9968 & Durbin-Watson stat & 0.286043 \\
Prob(F-statistic) & 0.000000 & & \\
\hline \hline
\end{tabular}

According to the regression results, the following estimating equation is obtained:

$$
\begin{gathered}
Y=631.5453+0.065308 X_{i} \\
(10.56384)(20.97610) \\
\mathrm{R}^{2}=0.960698 \quad \mathrm{DW}=0.286043 \quad \mathrm{~F}=204.7064
\end{gathered}
$$

Because $\mathrm{R}^{2}=0.960698$ and Adjusted R-squared $=0.958515$, both of which are close to 1 , this indicates that the model has very good fitting effect. And Prob(F-statistic) is 0.000000 , that reflects the high linearity of variables. It proves that the regression equation has notable regression effect. t-Statistic of regression coefficient indicates that tourist income has remarkable influence on GDP.

\subsubsection{Estimation of Confidence Interval of Parameters}

According to the variable significance testing: in the confidence coefficient of 1- $\alpha$, the confidence interval of $\beta$ is $\beta$. If given $\alpha=0.05$, check the table and get $\mathrm{t} \alpha / 2(18)=2.126$.

Based on the regression analysis, obtain $\beta 1=0.065308, \mathrm{~S} \beta 1=0.0213451$, so, the confidence interval of $\beta 1$ is calculated to be $(0.01992832,0.11068768)$.

3.1.5 Verification of Economic Significance

$$
\begin{gathered}
Y=631.5453+0.065308 X_{i} \\
(10.56384)(20.97610) \\
\mathrm{R}^{2}=0.960698 \quad \mathrm{DW}=0.286043 \quad \mathrm{~F}=204.7064
\end{gathered}
$$

Because $\beta 1$ is positive, tourist income is in direct proportion to GDP, and the value is in $(0,1)$.

And because $\beta 1=0.06508$, it indicates that, in the case of other factors staying the same, each one more unit of tourist income growth means 0.06508 GDP growth. In general, the model setting meets the economic significance and passes the verification of economic significance.

\subsubsection{Statistical Test}

(1) Test of goodness of fit

According to the regression results, $\mathrm{R}^{2}=0.960698$, Adjusted R-squared $=0.958515$. Both values are close to 1 , which means that the model has high goodness of fit. Otherwise, if both are close to 0 , the goodness of fit is poor.

Both R-squared and Adjusted R-squared are close to 1. This indicates that the regression model has high goodness of fit.

(2) F test

Assumption: $\mathrm{H} 0: \beta 1=0$, i.e. tourist income growth and GDP growth have no significant correlation; $\mathrm{H} 1: \beta 0 \neq 0$, i.e. tourist income growth and GDP growth have significant correlation.

F-statistic is determined based on the sample. Then, according to $F>F \alpha(k, n-k-1)$ or $F<F \alpha(k, n-k-1)$ (n: number of samples; k: number of explaining variables), reject or accept the original assumption $\mathrm{H} 0$.

Obtain $\mathrm{F}=439.997$ through calculation. Given significance level $\alpha=0.05$, check F-distribution table, and get the 
critical value F0.05(1.18) $=4.41$.

Obviously, $\mathrm{F}>\mathrm{F} \alpha(\mathrm{k}, \mathrm{n}-\mathrm{k}-1)$. It indicates that the linear relationship of the model is remarkably correct at the level of $95 \%$.

(3) t-statistic test

Regarding the explaining variable $\mathrm{X} 1$, according to the original assumption and alternative assumption $\mathrm{H} 0: \beta 1=0$, i.e. tourist income has no significant correlation with GDP; $\mathrm{H} 1: \beta 0 \neq 0$, i.e. tourist income has significant correlation with GDP.

Given a significance level $\alpha=0.05$, get the critical value $t \alpha / 2(n-k-1)$ (n: number of samples; $k$ : number of explaining variables). So, according to ItI $>t \alpha / 2(n-k-1)$ or $\mathrm{ItI} \leq \mathrm{t} \alpha / 2(\mathrm{n}-\mathrm{k}-1)$, decide to reject (or accept) the original assumption H0. Then, judge if the corresponding explaining variable should be included in the model.

Calculate variable X1 and get its value ItI $=20.976$ by software. Given significance level $\alpha=0.05$, check $\mathrm{t}$-distribution table, and find the critical value where the degree of freedom is 16 , get $t \alpha / 2(16)=2.120$. So, the $t$ value of $X 1$ is larger than the critical value. Thus, reject the original assumption, i.e. the explaining variables introduced into the model are all below the level $95 \%$. The influence is significant. It passes the variable significance test.

\section{Discussion and Implications}

According to the prediction results as shown in Figure 2, we can see that the curves show a steady rising trend. We can expect that Guizhou GDP and tourism income will continue to increase steadily.

In recent years, tourism service trade has gradually developed into the pillar industry of Guizhou economic development. It contributes more and more to the overall Guizhou economy. It is an indispensable part of the trade development of Guizhou. It is of great strategic significance for both the tourism enterprises and promotion of economic development driven by tourism. Based on the close relationship between Guizhou GDP and tourism income, Guizhou Province should take full advantage of its abundant tourism resources and grasp the opportunity of implementing the Western Development Policy, so as to bring unprecedented advantageous external conditions for Guizhou tourism. Taking hold of this historic moment, we should create an internal environment that is suitable for the development of tourism industry, and employ modern marketing methods and technologies to facilitate supernormal development of Guizhou tourism industry, finally pushing forward Guizhou GDP growth.

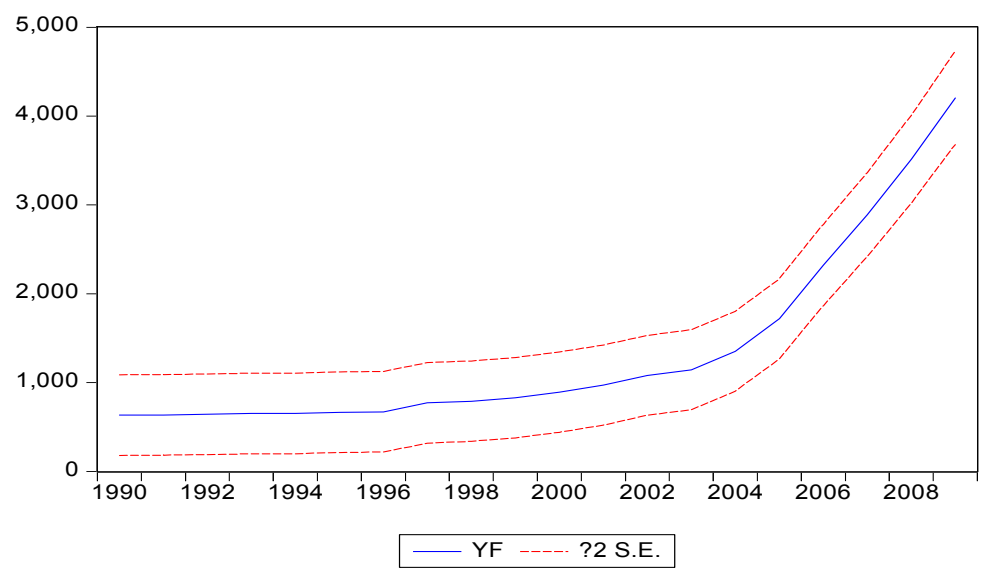

\begin{tabular}{|c|c|}
\hline \multicolumn{2}{|l|}{ Forecast: YF } \\
\hline \multicolumn{2}{|l|}{ Actual: Y } \\
\hline \multirow{2}{*}{\multicolumn{2}{|c|}{$\begin{array}{l}\text { Forecast sample: } 19902009 \\
\text { Included observations: } 20\end{array}$}} \\
\hline Included observations: 20 & \\
\hline Root Mean Squared Error & 207.7943 \\
\hline Mean Absolute Error & 169.3359 \\
\hline Mean Abs. Percent Error & 28.29889 \\
\hline Theil Inequality Coefficient & 0.060997 \\
\hline Bias Proportion & 0.000000 \\
\hline Variance Proportion & 0.010023 \\
\hline Covariance Proportion & 0.989977 \\
\hline
\end{tabular}

Figure 2. The forecast of GDP in Guizhou

\section{References}

Ballaguer, J., \& Cantavella-Jorda, M. (2002). Tourism as a long-run economic growth factor: the Spanish case. Applied Economics, 34, 877-884.

Bhagwati, J., \& Srinivasan, T. (1979). Trade policy and development. In R. Dornbush and J. Frenkel (Eds.), International Economic Policy: Theory and Evidence (pp.1-35). Johns Hopkins University press, Baltimore.

Dritsakis, N. (2004). Tourism as long-run economic growth factors: an empirical investigation for Greece using causality analysis. Tourism Economics, 10(3), 305-316. 
Harding, D., \& Pagan, A. (2003). A comparison of two business cycle dating methods. Journal of Economics \& Control, 27(9), 1681-1690.

Hou, G.S. (2000). Thoughts about Development Strategy of Guizhou Tourism. Journal of Guizhou Nationalities University, Supplement Issue.

Hu, X.H., \& Lin, X. (2013, March). A Study of the Relationship between Electricity Consumption and GDP Growth in Hainan International Tourism Island of China. Research in World Economy, 4(1), 109.

Narayan, P.K. (2004). Economic impact of tourism on Fiji's economy: empirical evidence from the computable general equilibrium model. Tourism Economics, 10(4), 419-433.

Pavlopoulos, P. (1999). The size and the dynamic of the tourism sector. Research institute for tourism (ITEP), Athens. (in Greek).

Sugiyarto, G., Blake, A., \& Sinclair, T. (2003). Tourism and globalization: economic impact in Indonesia. Annals of Tourism Research, 30(3), 683-702.

Thalassinos, E. (1991). Time Series Analysis. Stamoulis Publishings, Piraeus (in Greek).

Zhao, L.X. (2010). Guizhou Tourism Resource and Tourism Economy, Guizhou Ethnic Studies, 2001, 1st issue. Journal of Southwest Agricultural University (Social Science Edition), (5). 